\title{
ITINERÁRIO TERAPÊUTICO DA PESSOA ADULTA/IDOSA COM DEFICIÊNCIA MOTORA NA CIDADE DE FEIRA DE SANTANA- BA
}

\author{
$\underline{\text { Sarah Almeida Santos }}{ }^{1}$; Silvia da Silva Santos Passos ${ }^{2}$; Júlia de Paula Silva ${ }^{3}$ e Ayana \\ Araújo Lacerda ${ }^{4}$ \\ 1. Bolsista PIBIC/CNPq, Graduando em Enfermagem, Universidade Estadual de Feira de Santana, e-mail: \\ sarahsantosuefs@gmail.com \\ 2. Orientadora, Departamento de Saúde, Universidade Estadual de Feira de Santana, e-mail: \\ ssspassos@yahoo.com.br \\ 3. Participante do projeto Cuidado, Rede de Assistência à Saúde e Cotidiano de Pessoas com Deficiência Motora e suas \\ Famílias em Feira De Santana, Departamento de Saúde, Universidade Estadual de Feira de Santana, e-mail: \\ silvapaulladejulia@gmail.com
}

4. Participante do projeto Cuidado, Rede de Assistência à Saúde e Cotidiano de Pessoas com Deficiência Motora e suas Famílias em Feira De Santana, Departamento de Saúde, Universidade Estadual de Feira de Santana, e-mail: ayanalacerda@hotmail.com

PALAVRAS-CHAVE: itinerário terapêutico; deficiência motora; sistemas de cuidado.

\section{INTRODUÇÃO}

O termo deficiência é definido como toda e qualquer restrição, seja ela física, mental e/ou sensorial de caráter permanente ou transitório (BRASIL, 2015), já a deficiência motora é trazida por Passos (2016) como a dificuldade ou impossibilidade de mudar e/ou manter a posição do corpo, andar e deslocar-se, realizar autocuidados e tarefas domésticas.

A faixa etária mais acometida pela deficiência é a população idosa, o que reflete o envelhecimento populacional com consequente perda das funcionalidades (OLIVEIRA, 2012). Após o adoecimento, as pessoas e sua família passam a buscar recursos que os auxiliem no tratamento ou ajudem a enfrentá-lo, esses trajetos explorados para resolver suas necessidades de saúde, bem como a lógica como são traçados, sejam nas redes formais e/ou informais, de apoio, fazem parte do que se denomina itinerário terapêutico (THAINES et al., 2009).

Visando a importância da temática, foi realizada uma busca nas bases de dados nacionais: BVS (Biblioteca Virtual da Saúde), SCIELO (Scientific Electronic Library Online) no período de 18 a 20 de março de 2017, utilizando-se os descritores: Assistência à saúde, Locomoção, Pessoas com deficiência, com auxilio dos operadores booleanos "And" e "Or", foram encontrados 11 artigos referentes a temática, porém nenhum tratava da realidade baiana, o que demonstra uma fragilidade de estudos nesse estado sobre a temática em questão. Diante disso o objetivo desse estudo foi descrever o itinerário terapêutico da pessoa adulta/idosa com deficiência motora na cidade de Feira de Santana- Ba.

\section{METODOLOGIA}

Trata-se de um estudo descritivo-exploratório de abordagem qualitativa tendo como objeto de estudo o itinerário terapêutico da pessoa adulta/idosa com deficiência motora residente em Feira de Santana - BA.

Inicialmente a proposta da pesquisa, era analisar a rede de assistência à pessoa adulta/idosa com deficiência motora em Feira de Santana Bahia, porém devido à extensão deste objetivo que não poderia ser contemplado apenas na Estratégia de Saúde da Família, por se tratar de uma rede que perpassa a baixa, média e alta complexidade nas esferas tanto públicas quanto privadas, resolveu-se traçar o itinerário terapêutico dessas pessoas e assim 
identificar quais são os serviços de saúde bem como estratégias utilizadas no seu percurso em busca de apoio, tratamento e/ou diagnóstico.

Os critérios de inclusão dos participantes foram: ter algum tipo de deficiência motora, ser usuário da ESF da área de abrangência da Rua Nova. Os critérios de exclusão foram: ter algum tipo de limitação na fala e estar com condições clínicas que impossibilitassem a realização da entrevista.

A USF do Loteamento Morada Tropical não foi incluída, pois no período de coleta de dados a enfermeira estava de férias impossibilitando a localização das pessoas com deficiência motora dessa área de abrangência.

A USF Feira IX I, é composta por 6 microáreas, sendo que dessas uma está descoberta por afastamento de um agente comunitário por adoecimento, a USF Feira IX II, possui 5 microáreas, porém 3 estão descobertas. Das 2 microáreas cobertas, apenas uma participou da pesquisa, pois um dos agentes comunitários estava de férias no período da coleta de dados.

A técnica de coleta de dados foi a realização de uma entrevista semiestruturada, gravada, com os usuários, no domicilio, em local reservado, proposto por eles. As entrevistas foram posteriormente transcritas na íntegra e analisadas segundo a análise de conteúdo proposta por Barddin (2011).

Essa pesquisa respeitou os aspectos éticos da Resolução $n^{\circ} 466 / 12$ do Conselho Nacional de Saúde (BRASIL, 2012), e foi aprovada pelo Comitê de Ética em Pesquisa da Universidade Estadual de Feira de Santana Parecer n ${ }^{\circ}$ 2.086.906.

\section{RESULTADOS E DISCUSSÃO}

\begin{tabular}{|c|c|c|c|c|c|c|c|}
\hline Iniciais & Sexo & $\begin{array}{c}\text { Raça/co } \\
r\end{array}$ & Idade & Tipo de deficiência & Causa & Escolaridade & Renda \\
\hline E.B.S. & Masculino & Pardo & 58 anos & Hemiplegia direita & AVC & $2^{\circ}$ grau incompleto & 1a 3 salários mínimos \\
\hline E.M.S. & Masculino & Negro & 80 anos & Hemiplegia direita & AVC & Não alfabetizado & 1a 3 salários mínimos \\
\hline M. B & Feminino & Parda & 80 anos & $\begin{array}{l}\text { Hemiplegia esquerda e paresia em } \\
\text { perna direita }\end{array}$ & TCE & 10 grau incompleto & 1a 3 salários mínimos \\
\hline M.I.J.P & Feminino & Branca & 51 anos & Atrofia muscular & $\begin{array}{l}\text { Distrofia Miotônica } \\
\text { (Doença de } \\
\text { Steinert) }\end{array}$ & 20 grau incompleto & 1a 3 salários mínimos \\
\hline R.M. & Feminino & Parda & 58 anos & Paraplegia & $\begin{array}{l}\text { Lesãomedular } \\
\text { (errocirúrgico) }\end{array}$ & 20 grau incompleto & 1a 3 salários mínimos \\
\hline F. A. & Masculino & Pardo & 57 anos & $\begin{array}{l}\text { Desgaste na articulação do joelho } \\
\text { direito }\end{array}$ & Osteoartrite & 1grau completo & 1a 3 salários mínimos \\
\hline J.P.L. & Masculino & Negra & 75 anos & Ferimento crônico em pé direito & Erisipela eTVP & 10 grau incompleto & 1a 3 salários mínimos \\
\hline $\begin{array}{l}\text { E.M.M. } \\
\text { B }\end{array}$ & Feminino & Negra & 54 anos & Má formação na perna esquerda & Congênita & 29 incompleto & 1a 3 salários mínimos \\
\hline A.C.P.O & Masculino & Negra & 73 anos & Amputação da perna esquerda & $\begin{array}{l}\text { Complicação do } \\
\text { diabetes }\end{array}$ & $1^{\circ}$ grau incompleto & 1 a 3 salários mínimos \\
\hline M.C & Feminino & Parda & 67 anos & $\begin{array}{l}\text { Desgaste na articulação do joelho } \\
\text { direito }\end{array}$ & Osteoartrite & Não alfabetizada & 1a 3 salários mínimos \\
\hline S.M.S & Feminino & 40 anos & Negra & $\begin{array}{l}\text { Má formação em articulação de ambos } \\
\text { os joelhos (joelho em varo) }\end{array}$ & Congênito & 20 grau incompleto & 1a 3 salários mínimos \\
\hline M.J.B.C & Feminino & 73 anos & Negra & $\begin{array}{l}\text { Desgaste na articulação do joelho } \\
\text { esquerdo }\end{array}$ & Osteoartrite & Não alfabetizada & 1a 3 salários mínimos \\
\hline Z.L.S & Feminino & 83 anos & Parda & $\begin{array}{l}\text { Desgaste na articulação do joelho } \\
\text { esquerdo e pareșia em braço direito }\end{array}$ & $\begin{array}{l}\text { Osteoartrite e } \\
\text { lesãoemtendão }\end{array}$ & 10 grau incompleto & 1 a 3 salários mínimos \\
\hline M.C.S & Feminino & 75 anos & Negra & Desgaste na articulação do joelho & Osteoartrite & Não alfabetizada & 1a 3 salários mínimos \\
\hline
\end{tabular}


Para a construção das categorias, utilizamos o sistema de cuidados à saúde proposto por Kleiman (1980). Sendo assim, a partir da análise dos dados empíricos emergiu a seguinte a categoria: "Os sistemas de cuidados à saúde adotados por pessoas com deficiência motora", composta pelas subcategorias: "Sistema de Cuidado Profissional" e "Sistema de Cuidado Popular".

Os sistemas de cuidados fornecem às pessoas os caminhos para efetuar a interpretação de sua condição de saúde-doença e os possíveis percursos a serem traçados na busca por cuidados e tratamentos (CYPRIANO; MIOTELLO, 2011).

A interferência nas atividades de vida diária, seja pela presença de dor ou pela dificuldade motora em si, é o que motiva a procura pelo tratamento, sendo que o sistema de cuidado profissional é o primeiro buscado nesses casos, focando-se nas especialidades da área de saúde. Caso não interfira tanto no cotidiano, a busca por cuidado é postergada, podendo muitas vezes levar ao agravamento do quadro.

O sistema popular é utilizado não como alternativa ao sistema profissional mas sim como auxiliar a este, para o manejo da dor e promoção da cicatrização, sendo o método mais empregado o uso de chás. Além disso, a fé e a religião aparecem não somente para a busca da cura através da prática de rituais, mas também como apoio para o enfrentamento das adversidades, confirmando a visão holística do ser humano, uma vez que este é mais que apenas físico, ele é um ser biopsicosocioespiritual.

\section{CONSIDERAÇÕES FINAIS}

Acreditamos que este estudo, além de promover a ampliação do conhecimento a cerca do itinerário terapêutico dessas pessoas, também proporcionará reflexão a cerca da valorização das práticas alternativas do cuidado, e do saber popular, contribuindo para a construção de uma prática em saúde baseada na educação popular em saúde, inserindo a pessoa como sujeito participante do seu plano terapêutico.

\section{REFERÊNCIAS}

BARDIN, L. Análise de conteúdo. Tradução por: Luis Antero Reto e Augusto Pinheiro. São Paulo. Edições 70, LDA, 2011.

BRASIL. Estatuto da pessoa com deficiência. Brasília: Senado Federal, Coordenação de Edições Técnicas, 65 p. 2015.

BRASIL. Ministério da Saúde. Diretrizes e normas regulamentadoras de pesquisas envolvendo seres humanos. Resolução 466/2012, Brasília, DF, 2012.

CYPRIANO, C.; MIOTELLO, D. Perfil de dissertações e teses sobre enfermagem e cultura do programa de pós-graduação de enfermagem da UFSC Florianópolis. 2011. Monografia (Graduação em Enfermagem) - Universidade Federal de Santa Catarina, Florianópolis.

PASSOS, S. S. S. Cuidado, rede de assistencia à saúde e cotidiano de pessoas com deficiência motora e suas famílias em feira de santana. 2016. 47p. Projeto de pesquisa, Universidade Estadual de Feira de Santana, 2016.

OLIVEIRA, L. M. B. Cartilha do censo 2010 - Pessoas com Deficiência. Brasília 2012. Disponível em: <http://www.pessoacomdeficiencia.gov.br/app/publicacoes/cartilha-do-censo2010-pessoas-com-deficiencia> acesso em 20 de março de 2017.

THAINES, G. H. L. S. et al. A busca por cuidado empreendida por usuário com diabetes mellitus - um convite à reflexão sobre a integralidade em saúde. Texto Contexto Enferm, v. 18, n. 1, p. 57-66, 2009. 